\title{
Familial aggregation of inflammatory bowel disease in patients with ulcerative colitis
}

\author{
Akshita Gupta, Sawan Bopanna, Saurabh Kedia, Dawesh Prakash Yadav, Sandeep Goyal, Saransh Jain, \\ Govind Makharia, Vineet Ahuja \\ Department of Gastroenterology, All India Institute of Medical Sciences, New Delhi, India
}

\begin{abstract}
Background/Aims: Familial occurrence of inflammatory bowel disease (IBD) is well documented. Reports from Western countries have shown a higher familial occurrence of ulcerative colitis (UC) in first- and second-degree relatives than that in the Asian UC population. No data are currently available from the Indian subcontinent in this regard. We present our data on the familial aggregation of UC. Methods: Records of patients with UC followed at the Inflammatory Bowel Disease Clinic at the All India Institute of Medical Sciences, New Delhi from August 2004 to January 2016 were reviewed. Details regarding the prevalence of family history and characteristics of these patients were recorded. Affected family members were contacted and disease characteristics were noted for assessment of familial aggregation. Results: Of the 2,058 UC patients included in the analysis, a positive family history of IBD was confirmed in 31 patients (1.5\%), 24 (77.4\%) of whom had only first-degree relatives affected. All the affected relatives had UC and none had Crohn's disease. Among first-degree relatives, siblings were found to have the highest prevalence of IBD (53.3\%), followed by parents (26.7\%). Conclusions: The probability of occurrence of IBD in family members of affected North Indian UC patients is lower than that reported in Western populations. (Intest Res 2017;15:388-394)
\end{abstract}

Key Words: Colitis, ulcerative; Medical history taking

\section{INTRODUCTION}

Inflammatory bowel disease (IBD) includes UC and CD, which are chronic idiopathic systemic diseases that involve chronic inflammation of the intestine. Although their etiopathogenesis remains an enigma, it is thought that they are complex polygenic disorders, involving interplay of environment, gut microbiota, and dysregulated immune activation in genetically predisposed individuals. ${ }^{1,2}$

Family history includes a combination of both genetic and environmental influences. A positive family history has been

Received July 27, 2016. Revised October 7, 2016.

Accepted October 12, 2016. Published online April 4, 2017

Correspondence to Vineet Ahuja, Department of Gastroenterology, All India Institute of Medical Sciences, Room No. 3093, Third Floor, Teaching Block,

New Delhi 110029, India. Tel: +91-11-26593300, Fax: +91-11-2658663,

E-mail:vineet.aiims@gmail.com

Financial support: None. Conflict of interest: None. found to be a strong risk factor for the development of IBD, more so for CD than UC., Increased disease concordance among monozygotic and dizygotic twins points strongly towards the role of genetics in the development of UC. ${ }^{5,6}$ Although genome-wide association studies have identified several overlapping loci that are associated with both UC and $\mathrm{CD}^{7}$ family history for UC is less well established as a risk factor than for $\mathrm{CD}$, and more studies are required.

The burden of IBD in India and other Asian countries is rising. ${ }^{8-10}$ Several studies from the West have determined the prevalence of IBD in the relatives of UC or CD patients. Data from Copenhagen report a 10-fold increase in the familial risk of UC. ${ }^{11}$ In a pediatric study in Greece that included 244 UC patients, $6.6 \%$ had a positive family history of UC. ${ }^{12}$ There are very few studies in the Asian population. The early course of disease in patients with IBD in Asia was found to be comparable to that in the West. ${ }^{13}$ However, the prevalence of an associated family history in the Asian population was

\footnotetext{
๑ Copyright 2017. Korean Association for the Study of Intestinal Diseases. All rights reserved.

This is an Open Access article distributed under the terms of the Creative Commons Attribution Non-Commercial License (http://creativecommons.org/licenses/by-nc/4.0)

which permits unrestricted non-commercial use, distribution, and reproduction in any medium, provided the original work is properly cited.
} 
found to be less than that in the Western population. ${ }^{14,15}$

There are currently no available data from India on the prevalence of family history in patients with UC. Thus, we undertook this study, with a large sample size, to assess the prevalence of UC in the first- and second-degree relatives of Indian patients with UC, and to study the phenotype and long-term disease behavior in those with a positive family history. The study of the familial aggregation of UC may be crucial in better elucidating the genetic component of this disease.

\section{METHODS}

\section{Study Population}

Patients with UC followed at the Inflammatory Bowel Disease Clinic at the All India Institute of Medical Sciences (AIIMS), New Delhi, from August 2004 to January 2016 formed the background population of this study. AIIMS is a tertiary care center, serving as a referral hospital for patients from all over North India. Diagnosis of UC was established on the basis of accepted clinical, endoscopic, radiological, and histological criteria. ${ }^{16}$

\section{Study Design and Data Collection}

This study is a retrospective analysis of a referral IBD registry. Relevant clinical data were obtained from medical records encompassing both the initial consultation as well as subsequent follow-up through the entire duration of care within the practice. The medical records are comprised of a system of files, with each patient assigned an IBD number. Each file contains detailed information about the patient's disease and follow-up, including name, age, sex, phone number, address, diagnosis, history, clinical examination, investigations, and ongoing treatment. Approval was obtained from the ethics committee before starting the study.

We reviewed the medical records of UC patients who had a positive family history of IBD. These were used to assess the prevalence of UC in the first- and second-degree relatives of patients with UC. When $\geq 2$ members of the same family were registered, the member in whom UC was first diagnosed was considered the proband, and the others were regarded as relatives. First-degree relatives comprised parents, children, or siblings; second-degree relatives included grandparent-grandchild, and aunt/uncle-niece/nephew. A positive family history was defined as a proband having at least one first- and second-degree relative with IBD.
Information was obtained on demography, age at onset of UC, age at diagnosis, duration of illness, extent, extraintestinal manifestations, surgery, number of first- and seconddegree relatives affected, and their diagnosis. Similar details were also obtained for each affected first-degree relative. We further collected information from the patients and their relatives by telephonic interviews, and interviewed them in person during their visit. Approval was given by the Institutional Ethics Committee.

\section{Statistical Analysis}

Categorical variables were compared between groups using the chi-square test. Continuous variables with normal distribution, e.g., age at onset, were compared using Student $t$-test for independent samples. However, a nonparametric test for independent samples, i.e., the Mann-Whitney U test, was used for continuous variables that did not have a normal distribution. The Spearman rank correlation coefficient was used to compare continuous clinical characteristics in patients and their relatives. A $P$-value was considered significant when less than 0.05. Statistical analysis was performed using STATA for Windows version 14.1 (StataCorp., College Station, TX, USA).

\section{RESULTS}

\section{Study Population}

We included a total of 2,058 patients with UC in this study, of whom $65.4 \%$ were male. The mean age at onset of symptoms was $32.2 \pm 12.1$ years, and at diagnosis was $32.5 \pm 12.1$

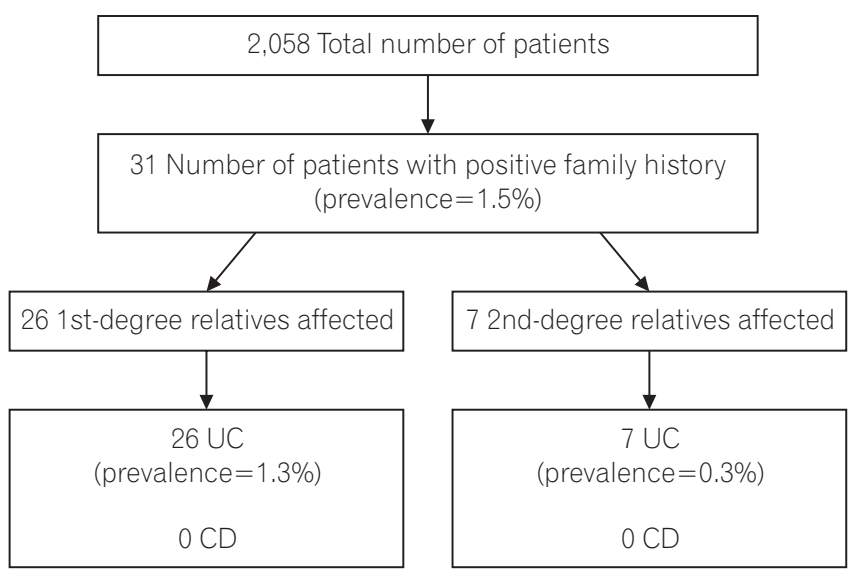

Fig. 1. Flow chart showing prevalence of family history of IBD in patients with UC. 
years. The mean duration of illness was $5.8 \pm 6.7$ years. The proportions of patients with proctitis, left-sided colitis, and extensive colitis were $14.8 \%, 42.3 \%$, and $42.9 \%$, respectively.

\section{Prevalence of IBD in First- and Second-Degree Relatives}

Of the 2,058 patients included in the analysis, a positive family history of IBD was confirmed in 31 patients (1.5\%), (Fig. 1) 24 (77.4\%) of whom had only first-degree relatives affected; 5 patients (16.1\%) had only second-degree relatives affected and 2 patients (6.5\%) had both first- and seconddegree relatives affected. Hence, the prevalence of IBD among first-degree relatives was $1.26 \%$, and among seconddegree relatives, $0.34 \%$. A total of 25 patients each had only 1 affected family member (80.7\%), while 6 patients each had 2 affected family members (19.4\%). All the affected relatives were diagnosed with UC; hence, the concordance for type of IBD was $100 \%$.

\section{Comparison of Clinical Features in Patients with Sporadic and Familial UC}

The proportion of male patients was significantly lower in familial cases $(38.7 \%)$ than in sporadic cases $(65.8 \%$, $P=0.002)$. There was no significant difference in mean age at onset $(33.0 \pm 9.7$ years vs. $32.2 \pm 12.1$ years, $P=0.400)$, and mean age at diagnosis $(35.1 \pm 10.5$ years vs. $32.5 \pm 12.1$ years, $P=0.100$ ). The extent of disease also varied significantly, with E3 disease being less common in familial cases (27.6\%) than in sporadic cases $(43.2 \%, P=0.002)$. Most patients $(79.3 \%)$ with familial UC had an intermittent flare type of disease course, whereas $13.8 \%$ and $6.9 \%$ had a chronic continu-

Table 1. Comparison of Clinical Features in Sporadic and Familial UC $(n=2,058)$

\begin{tabular}{|c|c|c|c|c|c|}
\hline & \multirow[b]{2}{*}{ Sporadic UC } & \multicolumn{3}{|c|}{ Familial UC } & \multirow[b]{2}{*}{$P$-value } \\
\hline & & All patients & $\begin{array}{l}\text { Patients with } 1 \text { st-degree } \\
\text { relatives affected }\end{array}$ & $\begin{array}{l}\text { Patients with } 2 \text { nd-degree } \\
\text { relatives affected }\end{array}$ & \\
\hline No. of patients & 2,027 & $31^{\mathrm{a}}$ & 26 & 7 & \\
\hline Male sex (\%) & 65.8 & 38.7 & 42.3 & 28.6 & 0.002 \\
\hline Age at onset (yr) & $32.2 \pm 12.1$ & $33.0 \pm 9.7$ & $33.8 \pm 9.9$ & $31.0 \pm 9.5$ & 0.400 \\
\hline Age at diagnosis (yr) & $32.5 \pm 12.1$ & $35.1 \pm 10.5$ & $35.7 \pm 11.4$ & $33.6 \pm 11.2$ & 0.100 \\
\hline Duration of illness (yr) & $5.8 \pm 6.6$ & $12.4 \pm 9.4$ & $11.8 \pm 9.3$ & $14.3 \pm 9.4$ & $<0.001$ \\
\hline Age at last follow-up (yr) & $38.3 \pm 12.9$ & $45.4 \pm 14.4$ & $45.5 \pm 15.0$ & $45.3 \pm 14.8$ & 0.003 \\
\hline Duration of follow-up (yr) & $5.6 \pm 6.7$ & $10.5 \pm 8.6$ & $9.9 \pm 8.6$ & $12.1 \pm 8.7$ & $<0.001$ \\
\hline Extent at diagnosis (\%) & & & & & 0.002 \\
\hline E1 (proctitis) & 14.4 & 37.9 & 37.5 & 28.6 & \\
\hline E2 (left-sided colitis) & 42.4 & 34.5 & 33.3 & 42.8 & \\
\hline E3 (extensive colitis) & 43.2 & 27.6 & 29.2 & 28.6 & \\
\hline$E I M+(\%)$ & 26.8 & 48.3 & 66.7 & 57.1 & 0.010 \\
\hline Surgery (\%) & 2.2 & 3.4 & 4.2 & 0 & 0.600 \\
\hline \multicolumn{6}{|l|}{ Ever use of medication (\%) } \\
\hline Mesalamine & 80.7 & 72.4 & 66.7 & 85.7 & 0.300 \\
\hline Other aminosalicylate & 16.6 & 17.2 & 16.7 & 14.3 & 0.900 \\
\hline Sulfasalazine & 11.5 & 6.9 & 4.2 & 14.3 & 0.400 \\
\hline Corticosteroids & 68.6 & 65.5 & 70.8 & 42.9 & 0.700 \\
\hline Azathioprine & 18.9 & 31.1 & 29.2 & 28.6 & 0.100 \\
\hline Infliximab & 0.6 & 0 & 0 & 0 & 0.700 \\
\hline Probiotics & 9.9 & 20.7 & 20.8 & 14.3 & 0.060 \\
\hline
\end{tabular}

Values are presented as mean \pm SD.

${ }^{a}$ Two patients had both 1st- and 2 nd-degree relatives affected.

EIM, extraintestinal manifestations. 
ous type or a single episode of UC, respectively. Nearly half (48.3\%) of the familial cases reported extraintestinal manifestation; the proportion was higher in patients with an affected first-degree relative (66.7\%), while it was significantly lower in sporadic cases $(26.8 \%, P=0.010)$. There were no significant differences in terms of surgery and the use of medications among the patients with and without a family history of UC (Table 1).

\section{First- and Second-Degree Relatives with UC: Clinical Characteristics}

The frequency of IBD among first- and second-degree relatives of patients with UC according to type of relationship is shown in Table 2. Among first-degree relatives, siblings were found to have the highest prevalence of IBD (53.3\%), followed by parents (26.7\%), while offspring had the low-

Table 2. Frequency of IBD among First- and Second-Degree Relatives

\begin{tabular}{ll}
\hline & Frequency (\%) \\
\hline 1st-degree relatives & $9(30.0)$ \\
Brother & $7(23.3)$ \\
Sister & $5(16.7)$ \\
Father & $3(10.0)$ \\
Mother & $3(10.0)$ \\
Son & $3(10.0)$ \\
Daughter & \\
2nd-degree relatives & $1(12.5)$ \\
Grandfather & 0 \\
Grandmother & $2(25.0)$ \\
Uncle & $3(37.5)$ \\
Aunt & $1(12.5)$ \\
Nephew & $1(12.5)$ \\
Niece &
\end{tabular}

est prevalence (20\%). Among the second-degree relatives, highest prevalence of IBD occurred in uncle-aunt (62.5\%), followed by nephew-niece (25\%) and grandparents (12.5\%). The mean age of onset among family members was 29.2 years, the mean age at diagnosis was 30.5 years, and the duration of illness was 11.1 years. A relatively high proportion of affected family members (55\%) had extensive colitis; $35 \%$ had extraintestinal manifestations and $16.6 \%$ had undergone surgery. Extraintestinal manifestations were present in 14 $(48.27 \%)$ probands with UC and in $7(35 \%)$ of the affected first-degree relatives (Table 3).

\section{Concordance within Families}

Concordance for extent of disease was found in half of UC families (50\%). Similarly, concordance for extraintestinal manifestations was present in 9 of $18 \mathrm{UC}$ families (50\%). There was significant concordance for the mean duration of illness (63.8\%, $P=0.004$ ); however, concordance was low for the mean age at onset $(21.4 \%, P=0.3948)$ and the mean age at diagnosis $(19.4 \%, P=0.400)$. Among the parent-offspring relations, the age at onset (43.3 years vs. 27.1 years) and age at diagnosis (44.6 years vs. 28.6 years) varied significantly, while there was little variation among siblings.

\section{DISCUSSION}

Familial aggregations of diseases provide unique insights into the pathogenesis. Both environmental and genetic factors underlie the familial occurrence of a disease. IBD shows familial aggregation, which is well reported in various studies. Familial occurrences in ethnically unique populations are different. Various Asian studies have reported that the familial aggregation of UC is far less than that in the West. A study from India reported a definite family history in $2.3 \%$ of patients with UC. ${ }^{17}$ Further studies in this regard are re-

Table 3. Extraintestinal Manifestations in UC Patients and Their Family Members

\begin{tabular}{lcc}
\hline \multirow{2}{*}{ EIM } & UC patient $(\mathbf{n = 2 9 )}$ & \multicolumn{2}{c}{ 1st-degree relative $(\mathbf{n = 2 0 )}$} \\
\cline { 2 - 3 } \cline { 2 - 3 } Total & Frequency (\%) & Frequency (\%) \\
Peripheral and central arthralgias & $14(48.3)$ & $3(35.0)$ \\
Aphthous ulcers & $7(24.1)$ & $3(15.0)$ \\
Psoriasis & $5(17.2)$ & $1(5.0)$ \\
Pellagra & $1(3.5)$ & 0 \\
\hline
\end{tabular}

EIM, extraintestinal manifestations. 
quired from India and Asian countries. We undertook this study, therefore, to assess the prevalence of IBD among relatives of UC patients in India, and compared the baseline demographics as well as disease characteristics in familial and sporadic UC.

Of the 2,058 UC patients included in the study, a positive family history was found in $1.5 \%$. This was much lower than the familial IBD prevalence of $5 \%$ to $18 \%$ reported from Western countries. ${ }^{11,18-21}$ Among Asian populations, a study from Sri Lanka showed that a family history of IBD was present in $2.1 \%$ of UC patients, ${ }^{22}$ while a Japanese study reported $2.7 \%{ }^{15}$ In Korea, the prevalence of a positive family history of UC varied from $2.01 \%$ to $6.5 \%{ }^{14,23,24}$ A Chinese study reported that $1.48 \%$ of UC patients had a family history, which is similar to the prevalence we saw in our study. ${ }^{25}$ This shows that the prevalence of familial UC is slightly lower in Asian countries as compared to the West. Familial aggregation includes genetic factors as well as environmental influences; as people from the same family may have similar lifestyles and share the same environment, they may also be affected by the same environmental exposure. Genetic mutations differ between different ethnic backgrounds. For example, the HLA-DRB1 alleles associated with UC differ between Asian and Western countries. ${ }^{26-33}$ The NOD-2 mutation is not associated with CD in Japanese, ${ }^{34}$ Chinese, ${ }^{35}$ or Koreans, ${ }^{36}$ but an association has been identified in the Western populations. ${ }^{37,38}$ Thus, this diversity helps to better elucidate the genetic component of the disease and to assess the role of heredity in the etiopathogenesis of IBD, which can help optimize genetic counseling in the future.

Our study showed a $100 \%$ concordance for the type of IBD among probands of UC and their family members, as compared with a previous study in which concordance was $70 \%$ for UC. ${ }^{39}$ However, in some other studies a high concordance for both types of the disease was found. ${ }^{12,40,41}$ The disease susceptibility may therefore be specific, and patients with UC have a greater chance of a family member being affected by UC rather than CD.

In the present study, we investigated the differences in disease characteristics between patients with and without a family history. The proportion of male patients was significantly lower in familial cases (38.7\%) as compared to sporadic cases $(65.8 \%)$. However, the male to female ratio varied widely in different studies across populations. ${ }^{24,39,42}$ The age at onset and diagnosis did not vary significantly between those with and without a family history in our study, unlike previous studies that showed a younger age at onset for familial UC cases. ${ }^{12,15,24}$ Probands with a family history had a significantly lower proportion of extensive colitis (27.6\% vs. $43.2 \%$ ). Referral bias can explain the high proportion of extensive colitis and left-sided colitis in our study population. There were no significant differences in terms of outcomes such as surgery and use of medications, which is similar to the results of a study from South Korea. ${ }^{23}$

There are few data on similarities in UC families. A few studies report a high concordance for the extent of colonic involvement and presence of extraintestinal manifestations among family members. ${ }^{3,41}$ We arrived at similar conclusions in our study, with the concordance being $63.8 \%$ and $50 \%$ for extent of disease and presence of extraintestinal manifestations, respectively, in probands and their first-degree relatives. This further supports the view that UC arises in people with similar genetic or environmental predispositions.

In parent-offspring relationships, the ages at onset and diagnosis were found to be significantly lower in successive generations separated by more than 15 years in our study, but were almost the same among siblings. This could suggest a component of genetic anticipation in the development of UC. The concept of genetic anticipation implies an earlier onset and increased severity as the disease is passed through subsequent generations. ${ }^{43}$ However, no features of increased aggressiveness of disease were found in offspring compared with parents in our study.

We readily acknowledge a few limitations. This was a retrospective review of records of patients at a tertiary hospital. Therefore, the results may not be applicable to the general population. The clinical characteristics of first- and second-degree relatives were assessed mainly by telephonic interviews only. Having said this, the merits of our study are many. We included a large number of patients with UC from North India, and therefore enable a good estimate of the familial occurrence of IBD. Hence, there is direct clinical relevance, as the findings provide a risk estimate in our population, which will be invaluable in patient counseling.

In conclusion, a positive family history of IBD was confirmed in 31 (1.5\%) of our patients with UC, which is lower than that reported from Western populations. All relatives of affected patients had UC and none had CD, showing a high concordance rate. The differences between various populations in familial aggregation may be due to either genetic or environmental factors. Studying these differences may help in better elucidating the etiopathogenic mechanisms of IBD. 


\section{REFERENCES}

1. Danese S, Fiocchi C. Etiopathogenesis of inflammatory bowel diseases. World J Gastroenterol 2006;12:4807-4812.

2. Shih DQ, Targan SR, McGovern D. Recent advances in IBD pathogenesis: genetics and immunobiology. Curr Gastroenterol Rep 2008;10:568-575.

3. Annese V, Andreoli A, Astegiano M, et al. Clinical features in familial cases of Crohn's disease and ulcerative colitis in Italy: a GISC study. Italian Study Group for the Disease of Colon and Rectum. Am J Gastroenterol 2001;96:2939-2945.

4. Sachar DB. Crohn's disease: a family affair. Gastroenterology 1996;111:813-815.

5. Orholm M, Binder V, Sørensen TI, Rasmussen LP, Kyvik KO. Concordance of inflammatory bowel disease among Danish twins: results of a nationwide study. Scand J Gastroenterol 2000;35:1075-1081.

6. Tysk C, Lindberg E, Järnerot G, Flodérus-Myrhed B. Ulcerative colitis and Crohn's disease in an unselected population of monozygotic and dizygotic twins: a study of heritability and the influence of smoking. Gut 1988;29:990-996.

7. Jostins L, Ripke S, Weersma RK, et al. Host-microbe interactions have shaped the genetic architecture of inflammatory bowel disease. Nature 2012;491:119-124.

8. Ahuja V, Tandon RK. Inflammatory bowel disease: the Indian augury. Indian J Gastroenterol 2012;31:294-296.

9. Ahuja V, Tandon RK. Inflammatory bowel disease in the AsiaPacific area: a comparison with developed countries and regional differences. J Dig Dis 2010;11:134-147.

10. Ng SC, Leung WK, Shi HY, et al. Epidemiology of inflammatory bowel disease from 1981 to 2014: results from a territory-wide population-based registry in Hong Kong. Inflamm Bowel Dis 2016;22:1954-1960.

11. Orholm M, Munkholm P, Langholz E, Nielsen OH, Sørensen TI, Binder V. Familial occurrence of inflammatory bowel disease. N Engl J Med 1991;324:84-88.

12. Roma ES, Panayiotou J, Pachoula J, et al. Inflammatory bowel disease in children: the role of a positive family history. Eur J Gastroenterol Hepatol 2010;22:710-715.

13. Ng SC, Zeng Z, Niewiadomski O, et al. Early course of inflammatory bowel disease in a population-based inception cohort study from 8 countries in Asia and Australia. Gastroenterology 2016;150:86-95.e3.

14. Park JB, Yang SK, Byeon JS, et al. Familial occurrence of inflammatory bowel disease in Korea. Inflamm Bowel Dis 2006;12:1146-1151.
15. Kuwahara E, Asakura K, Nishiwaki Y, et al. Effects of family history on inflammatory bowel disease characteristics in Japanese patients. J Gastroenterol 2012;47:961-968.

16. Dignass A, Eliakim R, Magro F, et al. Second European evidence-based consensus on the diagnosis and management of ulcerative colitis part 1: definitions and diagnosis. J Crohns Colitis 2012;6:965-990.

17. Makharia GK, Ramakrishna BS, Abraham P, et al. Survey of inflammatory bowel diseases in India. Indian J Gastroenterol 2012;31:299-306.

18. Monsén U, Broström O, Nordenvall B, Sörstad J, Hellers G. Prevalence of inflammatory bowel disease among relatives of patients with ulcerative colitis. Scand J Gastroenterol 1987;22:214218.

19. Yang H, McElree C, Roth MP, Shanahan F, Targan SR, Rotter JI. Familial empirical risks for inflammatory bowel disease: differences between Jews and non-Jews. Gut 1993;34:517-524.

20. Roth MP, Petersen GM, McElree C, Vadheim CM, Panish JF, Rotter JI. Familial empiric risk estimates of inflammatory bowel disease in Ashkenazi Jews. Gastroenterology 1989;96:10161020.

21. Russel MG, Pastoor CJ, Janssen KM, et al. Familial aggregation of inflammatory bowel disease: a population-based study in South Limburg, the Netherlands: the South Limburg IBD Study Group. Scand J Gastroenterol Suppl 1997;223:88-91.

22. Niriella MA, De Silva AP, Dayaratne AH, et al. Prevalence of inflammatory bowel disease in two districts of Sri Lanka: a hospital based survey. BMC Gastroenterol 2010;10:32.

23. Chung SH, Park SJ, Lee HS, et al. Similar clinical characteristics of familial and sporadic inflammatory bowel disease in South Korea. World J Gastroenterol 2014;20:17120-17126.

24. Hwang SW, Kwak MS, Kim WS, et al. Influence of a positive family history on the clinical course of inflammatory bowel disease. J Crohns Colitis 2016;10:1024-1032.

25. Jiang XL, Cui HF. An analysis of 10218 ulcerative colitis cases in China. World J Gastroenterol 2002;8:158-161.

26. Myung SJ, Yang SK, Jung HY, et al. HLA-DRB1*1502 confers susceptibility to ulcerative colitis, but is negatively associated with its intractability: a Korean study. Int J Colorectal Dis 2002;17:233-237.

27. Futami S, Aoyama N, Honsako Y, et al. HLA-DRB1*1502 allele, subtype of DR15, is associated with susceptibility to ulcerative colitis and its progression. Dig Dis Sci 1995;40:814-818.

28. Yoshitake S, Kimura A, Okada M, Yao T, Sasazuki T. HLA class II alleles in Japanese patients with inflammatory bowel disease. Tissue Antigens 1999;53(4 Pt 1):350-358. 
29. Satsangi J, Welsh KI, Bunce M, et al. Contribution of genes of the major histocompatibility complex to susceptibility and disease phenotype in inflammatory bowel disease. Lancet 1996;347:1212-1217.

30. Cottone M, Bunce M, Taylor CJ, Ting A, Jewell DP. Ulcerative colitis and HLA phenotype. Gut 1985;26:952-954.

31. De La Concha EG, Fernandez-Arquero M, Santa-Cruz S, et al. Positive and negative associations of distinct HLA-DR2 subtypes with ulcerative colitis (UC). Clin Exp Immunol 1997;108:392-395.

32. Liu JZ, van Sommeren S, Huang H, et al. Association analyses identify 38 susceptibility loci for inflammatory bowel disease and highlight shared genetic risk across populations. Nat Genet 2015;47:979-986.

33. Juyal G, Negi S, Sood A, et al. Genome-wide association scan in north Indians reveals three novel HLA-independent risk loci for ulcerative colitis. Gut 2015;64:571-579.

34. Inoue N, Tamura K, Kinouchi Y, et al. Lack of common NOD2 variants in Japanese patients with Crohn's disease. Gastroenterology 2002;123:86-91.

35. Leong RW, Armuzzi A, Ahmad T, et al. NOD2/CARD15 gene polymorphisms and Crohn's disease in the Chinese population. Aliment Pharmacol Ther 2003;17:1465-1470.
36. Croucher PJ, Mascheretti S, Hampe J, et al. Haplotype structure and association to Crohn's disease of CARD15 mutations in two ethnically divergent populations. Eur J Hum Genet 2003;11:616.

37. Hugot JP, Chamaillard M, Zouali H, et al. Association of NOD2 leucine-rich repeat variants with susceptibility to Crohn's disease. Nature 2001;411:599-603.

38. Ogura Y, Bonen DK, Inohara N, et al. A frameshift mutation in NOD2 associated with susceptibility to Crohn's disease. Nature 2001;411:603-606.

39. Henriksen M, Jahnsen J, Lygren I, Vatn MH, Moum B; IBSEN Study Group. Are there any differences in phenotype or disease course between familial and sporadic cases of inflammatory bowel disease? Results of a population-based follow-up study. Am J Gastroenterol 2007;102:1955-1963.

40. Palli D, Saieva C, Trallori G, et al. A population-based study of familial clustering of inflammatory bowel disease in florence. Eur J Public Health 1997;7:109-112.

41. Satsangi J, Grootscholten C, Holt H, Jewell DP. Clinical patterns of familial inflammatory bowel disease. Gut 1996;38:738-741.

42. Andreu M, Márquez L, Domènech E, et al. Disease severity in familial cases of IBD. J Crohns Colitis 2014;8:234-239.

43. Höweler CJ, Busch HF, Geraedts JP, Niermeijer MF, Staal A. Anticipation in myotonic dystrophy: fact or fiction? Brain 1989;112(Pt 3):779-797. 